\title{
Sorpresas en Paraguay: I Simposio Internacional de Teatro
}

\section{Rosalina Perales}

En un festival reciente se presentó como tema de los eventos paralelos el cuestionamiento sobre la importancia de los festivales de teatro en el desarrollo del teatro hispano-latinoamericano. Saliendo del I Simposio Internacional de Teatro en Paraguay, nos hacemos la pregunta a la inversa: ¿simposios para qué? Se nos ocurre una docena de argumentos que los avalen, pero respecto al de Paraguay, lo más válido es la información extraída de esta relevante actividad, que en lugar de mantenerse aislada en el país de las arpas, puede difundirse entre los interesados del teatro paraguayo que no han tenido la ocasión de llegar hasta allí.

Transcurrieron 20 años entre mi primer viaje a Paraguay a conocer y estudiar su teatro, en tiempos tristes, cuando me recomendaban ahorrarme el viaje porque en Paraguay "no había teatro." Fui para constatar que sí había teatro, que aunque poco y esforzado contaba con teatristas de gran corazón que hacían malabares para levantar el teatro independiente, el social, el moderno. Unos triunfaron, otros se quedaron en la marcha, pero el esfuerzo no fue vano, pues este primer simposio y las actividades a las que pudimos asistir comprobaron que sigue existiendo el teatro en Paraguay, ahora con más ímpetu. Nuevos grupos y dramaturgos, así como una gran diversidad en los estilos tratados dentro de la escena lo demuestran.

Los intereses del Simposio fluctuaron entre los de los organizadores y los del público. Los primeros buscaban poner en contacto los teatristas y críticos del país con los estudiosos del teatro latinoamericano para compartir experiencias en torno al bilingüismo teatral. El público anhelaba la oportunidad de discutir al máximo la situación teatral del país, aprovechando para escuchar las observaciones de los visitantes. Se mostró cierto interés por el bilingüismo, pero más por los desniveles del teatro local, las carencias, la falta de apoyo, su ausencia en el extranjero. 
El Simposio, auspiciado por el Centro Paraguayo de Teatro (CEPATE) duró tres días, del 3 al 6 de mayo de 2006, en las facilidades del Instituto Paraguayo-Americano. Hubo un total de cinco mesas en las que se discutió en torno al teatro bilingüe en Paraguay y Estados Unidos. El reconocido antólogo y periodista del teatro paraguayo, Antonio Pecci, presentó una conferencia ilustrada fotográficamente, en la que presentó a los fundadores e impulsores del teatro bilingüe paraguayo. Confirmó como pioneros a Julio Correa en la dramaturgia y a Roque Centurión Miranda como el forjador actores, a la vez que se estableció como hecho que el teatro guaraní está basado en la resistencia cultural. Su recuento a base de fotos de teatristas y montajes importantes a través de los años, llegó hasta la actualidad. Mencionó textos y montajes destacables en ese camino bilingüe, como los de Rudi Torga, Alcibíades González del Valle, Antonio Escobar Cantero, etc. El grito del Luisón de Gónzález del Valle quedó como la obra esencial de ese trayecto. Datos como que el viaje a Manizales que hace en los años 60 Un puñado de tierra, texto bilingüe del grupo Teatro de Vanguardia, fue el detonante de una nueva era que impulsa al teatro bilingüe, resultaron iluminadores.

Se habló de un indispensable libro de historia sobre el teatro, El teatro paraguyo de ayer y de hoy, de Teresa Méndez Faith, que no logramos ver, pero que imaginamos escrito después de la documentación erudita de Josefina Pla. Está escrito en español y guaraní, con énfasis en este tipo de teatro bilingüe. Esta manifestación bilingüe crea una dramaturgia para un público dual, por eso se escribe en el idioma de otra cultura, el que a veces no es "totalmente conocido, compartido o respetado" por el que escribe, expresó un participante. Otra posición presentada en la discusión fue la de que en Paraguay hoy hay un desprecio por el teatro guaraní, difícil de admitir porque se quiere ver como una comunidad transnacional. Otros dijeron que sí hay teatro bilingqe, pero que es invisible porque la prensa no lo cubre. Se alegó, sin embargo, que en la prensa ya no se da espacio para cubrir nada de teatro, ni guaraní ni de ningún tipo, situación que vemos como globalizada.

Una de las mesas sirvió de homenaje al fenecido Augusto Roa Bastos. Sus obras Hijo de hombre y Yo el supremo, escritas en español, pero con espíritu guaraní son novelas para las cuales se hacen libretos. Hay varios por cada una, con sus respectivos montajes. Se observaron discrepancias entre los paraguayos respecto a los montajes, pero mucho interés en la discusión del trabajo de Roa Bastos narrador, en términos del biculturalismo paraguayo y sus relaciones con el teatro. Fue el tema y el panel que más interés desató durante el Simposio. 


\section{Teatro bilingüe en los Estados Unidos}

Un grupo de estudiosos del teatro latino en Estados Unidos fuimos invitados al I Simposio Internacional de Teatro en Paraguay para hablar de nuestras experiencias, investigaciones y opiniones sobre el bilingüismo anglohispano en este país. George Woodyard, Beatriz Rizk (una de las organizadoras de la actividad), Kirsten Nigro y quien escribe tuvimos oportunidad de expresarnos en torno al tema de acuerdo con las investigaciones que llevamos a cabo en este momento. El profesor Woodyard conversó en torno a la comunidad dominicana y su expresión teatral en Estados Unidos. Nos reveló nombres bastante desconocidos que han aflorado con fuerza en las comunidades dominicanas y en su investigación, como Claudio Miller, Chiqui Vicioso (que sí es conocida en ambas orillas, la dominicana y la neoyorquina) y José Báez, de cuyo Mondongo Scam desarrolló su trabajo: la lucha por sobrevivir del dominicano que trabaja en los Estados Unidos.

La profesora Kirsten Nigro entonó un tema de profundo interés, el teatro de la frontera entre México y Estados Unidos, que se hace en la actualidad. Nombró dramaturgos jóvenes y maduros que se han instalado en esa geografía, como Hugo Salcedo, o que trabajan con sus temáticas, aunque no vivan allí. El tema más candente en la zona es el feminicidio, más conocido en Ciudad Juárez. Ella lo ve como el resultado de la independencia económica y personal que desarrollan las maquiladoras en su enfrentamiento con el tradicional machismo mexicano, lo que provoca un ambiente de violencia contra la mujer trabajadora y, más adelante, contra todas. El mejor ejemplo que se ofreció fue el de Perla de la Rosa con Las muertes de Juárez.

La investigadora Beatriz Rizk habló de los elementos teóricos que dieron pie al título de la actividad - "La construcción de alteridad en un contexto transnacional: teatro latino/Latinoamericano en la era de la globalización" - y de las manifestaciones latinas en Estados Unidos, en general. Anunció las organizaciones que apoyan y facilitan la existencia y presentación del teatro latino en distintas instancias de la cultura nortemericana, más que nada en las ciudades con grandes concentraciones de hispanos como Nueva York, Chicago, Texas, Los Angeles o Miami. Comentó que NALAC o la "National Association of Latino Arts and Culture" es una organización de impulso cultural - que incluye actividades teatrales imprescindible para el latino de hoy.

En mi exposición traté de explicar los orígenes y características generales del desarrollo del teatro "newyorican" o teatro puertorriqueño en los Estados Unidos, desde la fundación del Puerto Rican Traveling Theatre, 
hasta el triunfo actual del grupo Pregones. Dado el breve tiempo para nuestras exposiciones, concluí con el trabajo de poesía-performance y posterior teatro de Pedro Pietri, no sin mencionar algunos de los nombres fundamentales de este momento: Edwin Sánchez, Migdalia Cruz y José Rivera. Las conclusiones paraguayas sobre nuestras ponencias sintonizaron en recomendar el estudio y lecturas dramatizadas de los textos y teatralidades que resultaron desconocidos en Paraguay, pero en los que encontraron ideas y sentimientos homólogos.

En otro panel el director Agustín Núñez habló de su experiencia bilingüe en el Teatro de la Luna, en Washington. Víctor Bogado, estudioso del teatro y director de teatro infantil examinó la globalización en el teatro paraguayo, tema que recibió mucha oposición, sobre todo de los locales.

Es magnífico que los simposios y congresos sobre teatro latinoamericano hayan incorporado el elemento práctico. Las muestras teatrales del país que auspicia el Simposio expande los límites del crítico que en ocasiones trabaja con el texto porque no tiene la oportunidad de verlos escenificados. Eso ocurrió en Paraguay, donde alcanzamos a ver cinco presentaciones teatrales en Asunción, además de un ensayo que resultó magnífico. Kuña Rekove (Vidas de mujer), de Edda de los Ríos, la organizadora del Simposio, mostró unos frescos sobre la campesina guaraní y las dificultades que les causa la falta de educación. Las veladas se desarrollaron en los años treinta como "manifestación popular que combinaba música, danza, poesía en guaraní, magia, monólogos cómicos, breves pasos de comedia y en ocasiones sátira crítica. Este espectáculo múltiple que se acercaba a la Comedia del arte italiano era llevado de pueblo en pueblo por los actores, incorporando al público" y fue inspirador para el desarrollo del teatro paraguayo (R. Perales $T H C$ Vol I, 206). La velada que vimos, aunque un recuerdo de lo que hemos descrito, fue exquisita; un banquete actoral, especialmente de los varones. Aun cuando las piezas eran en guaraní, el sobresaliente trabajo de los actores provocó nuestras carcajadas. Fue el mejor trabajo actoral de conjunto que tuvimos la oportunidad de ver. Hijo de hombre de Augusto Roa Bastos y bajo la dirección de José Luis Ardissone fue impecable en su dirección, pero el montaje en general resultó muy setentista; clamaba por actualización; por ubicarse en el siglo XXI. Wal Mayans, educado teatralmente en la escuela del Odin Teatret, bajo la dirección de Eugenio Barba resultó un buen discípulo, pues los trabajos que vimos (con mucho aire oriental) eran hermosos, con magia y rigor corporal, y una seriedad teatral a 
toda prueba. Un modelo refrescante (aunque tardío) dentro de la escena paraguaya.

Asistimos a un ensayo de Metro cuadrado del grupo $\mathrm{Nhi} \mathrm{Mu}$, dirigido por Patricia Masera, que resultó modernísimo, actualizado y hasta adelantado; un teatro corporal e imaginativo cargado de técnicas circenses (acrobacia) y de recursos del clown, unidos al teatro imagen, para presentar temas jóvenes a su joven público. Habría que vigilar el desarrollo de este conjunto y escribir más sobre su trabajo. Un verdadro deleite.

Para hacer un balance justo de la actualidad paraguaya que vivimos en unos pocos días hay que decir que el lento desarrollo que hubo en sus orígenes tanto en español como en guaraní, empezó a superarse desde los años ochentas, con los cambios históricos del país. Hoy día, sin que haya un gran movimiento teatral, se puede decir que hay manifestaciones en todos los tipos de teatro; hay más grupos; los teatristas salen a estudiar al extranjero y regresan a presentar un nuevo teatro y a preparar jóvenes. Autores como Moncho Arzuaga sobresalen con una producción moderna y continua. Grupos como El Arlequín Teatro se mantienen con la cartelera abierta, uniendo su producción veterana a la de otros nuevos conjuntos como el Camarín Teatro de Asunción. Hay teatro comercial con su público estable, al igual que en el resto del mundo, pero también hay comedia de alta calidad. Se presentan teatristas nuevos con temas modernos (sobre todo, urbanos) junto al teatro mítico-folklórico o los clásicos, todo, en español y en guaraní. Aunque, como dijo alguien, las oligarquías en la política y la cultura siguen vigentes con o sin dictadura, el pueblo teatral se mantiene en pie de lucha porque el impulso que ha adquirido el teatro paraguayo no tiene vuelta atrás.

\section{Universidad de Puerto Rico}

